\title{
GÊNERO E MÍDIA: FEMINISMO E O JORNALISMO DA REVISTA REALIDADE DURANTE O REGIME MILITAR (1966-1976)
}

\section{Gender And Media: Feminism And Journalism Reality Magazine During The Military Regime}

Felipe Araújo ${ }^{23}$

Nanci Stancki da Luz $^{24}$

\section{Resumo:}

Este artigo é parte de um trabalho dissertativo que investiga as representações de mulher no jornalismo impresso brasileiro, tendo como escopo a revista Realidade, publicada mensalmente durante dez anos entre 1966 e 1976 . No presente trabalho, fazemos uma investigação sobre as especificidades do feminismo no Brasil, tentando demonstrar o quanto a Realidade dialogava com as demandas das questões que envolviam a dominação masculina e a

23 Mestre em Tecnologia (PPGTE/UTFPR); Mestre em Comunicação e Linguagens (UTP) - Formado em História (UFPR) e Jornalismo (PUC-PR). E-mail: feliaraujo@gmail.com. pelo Centro Universitário Curitiba (2009), mestrado em Tecnologia pela Universidade Tecnológica Federal do Paraná (2000), doutorado em Política Científica e Tecnológica pela Universidade Estadual de Campinas (2005) e pós- doutorado em Política Científica e Tecnológica na Unicamp (2011) . Atualmente é docente e vice-coordenadora do Programa de Pós-graduação em Tecnologia (PPGTE), professora do Departamento Acadêmico de Matemática da Universidade Tecnológica Federal do Paraná (UTFPR), membro eleito do Conselho Universitário da UTFPR, tesoureira da ESOCITE.BR(Associação Brasileira de Estudos Sociais das Ciências e das Tecnologias) e da SINDUTF-PR (Seção Sindical dos Docentes da Universidade Tecnológica Federal do Paraná), coordenadora do Grupo de Estudos e Pesquisas sobre Relações de Gênero e Tecnologia (GETEC), editora dos "Cadernos de Gênero" (publicação do PPGTE), membro da Comissão de Estudos sobre Violência de Gênero da OAB-PR, advogada. Tem experiência na área de Educação, atuando principalmente nos seguintes temas: gênero e trabalho, divisão sexual do trabalho, violência de gênero, trabalho e tecnologia. E-mail: nancist@terra.com.br 
submissão da mulher. Partimos de uma perspectiva que o feminismo é uma das principais fontes causadoras de crise na sociedade patriarcal, apesar da complexidade do que é o feminismo, por suas diversas transversalidades na sociedade como um todo. A compreensão do contexto histórico é fundamental, pois o país vivia um período conservador, cujo governo era regido pelos militares, após o golpe de 31 de março de 1964.

Palavras-chave: Feminismo, Gênero e Mídia, Jornalismo, História do Brasil, Sociedade Patriarcal.

\section{Resumen:}

Este artículo es parte de un estudio de tesis de mestrado que investiga las representaciones de la mujer en el periodismo impreso brasileño, que tiene como objeto de pesquisa la revista Realidad, publicada mensualmente durante diez años entre 1966 y 1976. En este artículo, se realiza una investigación sobre los detalles del feminismo en Brasil, tratando de demostrar cómo la Realidad dialogó con las exigencias de las cuestiones relacionadas con el dominio masculino y la sumisión femenina. Partimos de una perspectiva de que el feminismo es una de las principales fuentes de crisis en la sociedad patriarcal, a pesar de la complejidad de lo que el feminismo es, por su transversalidad varios en la sociedad en su conjunto. Entender el contexto histórico es fundamental, ya que el país experimentó un período conservador, cuyo gobierno fue administrado por los militares tras el golpe de 31 de marzo de 1964.

Palabras Clave: Feminismo, Género y Media, Periodismo, Historia de Brasil, Sociedad Patriarcal.

\section{Introdução}

O presente artigo é parte de um trabalho dissertativo sobre gênero e jornalismo impresso brasileiro, em que tomamos como escopo a revista $R e-$ alidade, publicada pela editora Abril durante dez anos, no período que vai de 1966 a 1976. A história desta revista é um capítulo à parte do jornalismo brasileiro, pois modificou o fazer jornalístico e os conceitos de noticiabilidade na imprensa nacional. Estes, porém, são temas que não caberão no curto espaço proposto.

Em recentes reuniões de nosso grupo de pesquisa em Gênero e Tec- 
nologia, o GETEC-PPGTE, debatemos sobre a necessidade de levantar questões importantes para a história do movimento feminista no Brasil, pois entendemos que ainda existe muito a fazer para resgatar o histórico das organizações de mulheres em solo tupiniquim. Este trabalho vai nesse sentido, apresentando um alento da profissão de jornalista, tão ligada a momentos sórdidos de nossa história. Isto porque em nossa investigação, detectamos que a revista Realidade estava de acordo com as demandas do feminismo em suas páginas.

\section{Sociedade Patriarcal: Realidade e a condição da mulher}

Entendemos que a estrutura androcêntrica predomina nas sociedades constituídas pela humanidade. Em um processo histórico de longa duração - a história da própria humanidade - a família, ligada por laços de parentesco e regrada pela proibição do incesto, foi-se constituindo pouco a pouco em uma instituição centrada na figura do homem-pai, que teria direito de impor sua autoridade sobre os demais membros da casa:

O patriarcalismo é uma das estruturas sobre as quais se as-
sentam todas as sociedades contemporâneas. Caracteriza-se
pela autoridade, imposta institucionalmente, do homem sobre
mulher e filhos no âmbito familiar. Para que essa autoridade
possa ser exercida, é necessário que o patriarcalismo permeie
toda a organização da sociedade, da produção e do consumo
à política, à legislação e à cultura. Os relacionamentos inter-
pessoais e, consequentemente, a personalidade, também são
marcados pela dominação e a violência que têm sua origem
na cultura e instituições do patriarcalismo (CASTELLS, 2002:
169).

Veremos, pelos estudos de Castells, que através dos confrontos exercidos pelo feminismo contra a sociedade patriarcal, as estruturas milenares do comportamento humano tendem a sofrer alterações, sendo a dominação masculina um fenômeno social e cultural. Em nosso recorte histórico, o momento em que nos debruçamos (décadas de 1960 e 1970 no Brasil) é também o período em que o feminismo está se chocando contra a sociedade patriarcal, sendo, segundo Castells, um momento de crise desta sociedade centrada na figura do pai. 
As transformações nos processos de trabalho e as mudanças tecnológicas são fundamentais para esta mudança de concepção ou, se ainda não há mudança, ao menos colocam em crise a sociedade tal como se encontra. E dentro do mundo do trabalho, a sociedade, a incorporação maciça da mulher nos meios de produção "colocou um peso insustentável sobre os ombros da mulher, com suas quádruplas jornadas diárias (trabalho remunerado, organização do lar, criação dos filhos e a jornada noturna em benefício do marido)" (CASTELLS, 2002: 170):

A família patriarcal, base fundamental do patriarcalismo, vem sendo contestada neste fim de milênio pelos processos, inseparáveis, de transformação do trabalho feminino e da conscientização da mulher. As forças propulsoras desses processos são o crescimento de uma economia informacional global, mudanças tecnológicas no processo de reprodução da espécie e o impulso poderoso promovido pelas lutas da mulher e por um movimento feminista multifacetado, três tendências observadas a partir do final da década de 60 (CASTELLS, 2002:170).

Ao fragmentar a figura central do pai e do homem em uma sociedade, está se realizando também um descentramento, causador de uma crise de identidade. Para Hall há uma crise de identidade dupla que podemos perceber entre o confronto do feminismo com a sociedade patriarcal. Certamente que a realidade é mais complexa e os confrontos são múltiplos e simultâneos, contagiando-se mutuamente. Mas deste, em específico, há uma mudança na identidade do que é ser o sujeito mulher em busca de um novo espaço na sociedade enquanto que o homem passa a ser questionado em seu papel na sociedade patriarcal. Porém o próprio Hall afirma que a identidade plenamente unificada é uma fantasia, que se torna mais fragmentada à medida que "os sistemas de significação e representação cultural se multiplicam", colocando-nos diante de outras possibilidades identitárias com as quais poderíamos nos identificar.

Certamente as mídias, em suas diversas frentes da indústria cultural, são responsáveis imediatas pela promoção dessa multiplicidade de identidades apresentadas, ainda que ela esteja ideologicamente afinada com o capitalismo. Veremos, por exemplo, que enquanto as principais lideranças do movimento feminista brasileiro ainda se encontravam fora do país, em 1966, ou atuando em pequenas esferas sociais, a revista Realidade tomou como bandeira a iniciativa de questionar a condição de submissão da mu- 
Iher na sociedade vigente. Ressaltamos o termo "bandeira", pois foram diversas edições em que a situação da mulher foi um tema, não apenas para atrair o público feminino, já que a Realidade não se propunha como revista especializada, e sim de assuntos gerais, mas por uma afinidade ideológica da revista com questões feministas ou de indignação da condição em que se encontrava a mulher em nossa sociedade.

Não afirmamos que a Realidade era o marco zero das discussões feministas. Corroboramos o que afirma Hall ao tratar da multiplicação dos sistemas de significação e de sua relação com os confrontos identitários, incluindo, em prol do feminismo, a revista Realidade como uma multiplicadora de sentidos, ao menos até o final do ano de 1968. Mesmo em pleno governo de Médici, em 1971 (mês de maio), quando não se podia falar de reuniões de grupos organizados no Brasil, veremos que uma edição da revista é especialmente dedicada ao movimento feminista nos Estados Unidos, sendo até mesmo assunto de capa, com a chamada "Oriana Fallaci prevê a guerra das mulheres", seguida de texto em caixa alta em tamanho grande, como chamada principal "O INIMIGO É O HOMEM".

Oriana Fallaci foi a colaboradora estrangeira que mais participou de edições da Realidade, quase sempre tratando de assuntos internacionais. Não era parte da redação, mas tinha afinidades com os repórteres do veículo, tanto em se tratando de ideias quanto de estilo. Fallaci tornou-se uma reconhecida personalidade internacional, participando da Realidade falando sobre os Estados Unidos e a Guerra do Vietnã e, posteriormente, publicando uma série de perfis que vendia também para a revista italiana L'Europeu. Era ela mesma um exemplo de mulher ocupando espaços na Europa, enquanto no Brasil as redações jornalísticas - a Realidade não fugia sequer um pouco a esta regra - eram compostas majoritariamente por homens.

Outra "bandeira" da qual a revista Realidade não abriu mão, sendo questão fundamental na sociedade patriarcal, é relacionada ao divórcio. $R e-$ alidade colocou-se a favor do divórcio, não apenas para que os casais insatisfeitos pudessem seguir suas vidas, mas, ainda, para que a mulher, maior vítima do casamento falido, pudesse recomeçar novamente, havendo, nas reportagens desta mídia, uma preocupação relacionada ao preconceito contra a mulher desquitada. Para Castells, 
A dissolução dos lares, por meio de divórcio ou separação dos casais, constitui o primeiro indicador de insatisfação com um modelo familiar baseado no comprometimento duradouro de seus membros. É certo que pode haver (e, na verdade, é essa a regra) um patriarcalismo sucessivo: a reprodução do mesmo modelo com diferentes parceiros. No entanto, as estruturas da dominação (e mecanismos de confiança) se enfraquecem com essa experiência, tanto em relação às mulheres como aos filhos, frequentemente apanhados por lealdades conflitantes. Além disso, com frequência cada vez maior, a dissolução dos casamentos leva à formação de lares de solteiros ou lares com apenas um dos pais, cessando assim a autoridade patriarcal sobre a família, mesmo que as estruturas de dominação se reproduzam mentalmente no novo lar (CASTELLS, 1999: 173).

Segundo o autor, o divórcio é parte da crise da família patriarcal, com as crescentes insatisfações matrimoniais e suas dificuldades em compatibilizar casamento, trabalho e vida social, criando diversos relacionamentos sem casamento. Também, uma variedade de estruturas domésticas que diluem o modelo da família clássica, com lares de solteiros ou onde apenas um dos pais prolifera. E, finalmente, com a instabilidade familiar e a crescente autonomia das mulheres com relação ao seu comportamento reprodutivo, uma verdadeira crise dos padrões sociais de reposição populacional, aumentando, por outro lado, o número de crianças nascidas fora do casamento e geralmente sustentadas por suas mães. Este desenvolvimento social leva a um fortalecimento da mulher que se organizará socialmente. Para uma melhor compreensão desse fenômeno no Brasil durante o governo autoritário, no próximo tópico nos debruçaremos mais detidamente sobre a história do feminismo no Brasil.

\section{O feminismo, a Realidade e a crise na sociedade patriarcal}

O feminismo tem como compromisso pôr fim à dominação masculina e, portanto, à sociedade patriarcal. Ao longo das décadas de 1960 e 1970, o feminismo foi o componente de uma série de lutas urbanas e rurais que seguia em paralelo ou em conjunto com outras demandas sociais, estudadas amplamente por pesquisadores e acadêmicos. São exemplos de tais demandas o movimento estudantil; as lutas das ligas camponesas, que foram tema de diversos trabalhos; e as lutas operárias. No campo cultural não foi diferente. Artistas em diversos espaços específicos de atuação entremes- 
claram-se com as lutas urbanas, utilizando-se em diversos momentos dos aparatos da indústria cultural para expor mensagens engajadas, como na música, mas também nas artes plásticas e no teatro. A imprensa é mais um dos espaços sociais que, com suas contradições, também terá confrontos com o projeto social do governo militar, sendo este um de nossos focos de pesquisa e que, portanto, será debatido com profundidade no devido tempo.

Mas fato é que destas demandas sociais supracitadas, o feminismo é a que conta com maior dificuldade de se definir enquanto campo, principalmente ao tratarmos da década de 1960. Por ser um termo o qual "traduz todo um processo que tem raízes no passado, que se constrói no cotidiano, e que não tem um ponto predeterminado de chegada" (ALVES e PITANGUY, 1982: 7), sua luta subjetiva contra a opressão, que não se limita ao econômico, tem valor secundário dentro das militâncias da esquerda ortodoxa que viam no feminismo um divisionismo contra um inimigo maior na luta dual das classes. Possui proximidades com as questões de ordem do movimento negro, pois, assim como estes politizam o conceito de raça, o feminismo politizará também um conceito previamente entendido como biológico, qual seja, o sexo, pois aqui reside uma relação de poder, já que todas as relações interpessoais são relações de poder e hierarquia.

É um movimento flexível, que não se esgota em lutas militantes, tratando-se, muitas vezes, "de um discurso que subverte o lugar da mulher na história da humanidade, transformando assim o relacionamento historicamente predominante entre espaço e tempo" (CASTELLS, 2002: 230). Em qualquer dos casos, a defesa dos direitos da mulher é o ponto crucial do movimento.

Stuart Hall (2006), em seus estudos sobre identidade cultural na pós-modernidade, identifica o feminismo como uma questão central na sua ideia de descentramento do sujeito. Em sua análise do sujeito na pós-modernidade, ele afirma:

Um tipo diferente de mudança estrutural está transformando as sociedades modernas no final do século XX. Isso está fragmentando as paisagens culturais de classe, gênero, sexualidade, etnia, raça e nacionalidade, que, no passado, nos tinham fornecido sólidas localizações como indivíduos sociais. Estas transformações estão também mudando nossas identidades pessoais, abalando a ideia que temos de nós próprios como sujeitos integrados. Esta perda de 'um sentido de si' estável é chamada, algumas vezes, de deslocamento ou descentração 
do sujeito. Esse duplo deslocamento - descentração dos indivíduos tanto do seu lugar no mundo social e cultural quanto de si mesmos - constitui uma 'crise de identidade' para o indivíduo (HALL, 2006: 9).

Para Hall, esse deslocamento é ocasionado por uma série de rupturas nos discursos do conhecimento moderno, sendo cinco os grandes avanços na teoria social e nas ciências humanas e cujo maior efeito foi o descentramento final do sujeito cartesiano. Um importante descentramento seria ocasionado pelo feminismo, tanto como uma crítica teórica quanto como movimento social (HALL, 2006: 35-44).

Desta maneira, considerando acima de tudo a referida década de 1960 no Brasil, o feminismo não se restringia a movimentos organizados, ainda que contasse com a organização e sensibilidades de alguns movimentos de esquerda para expor as questões da mulher na sociedade. Todavia, mesmo que não fosse tão visível quanto as organizações estudantis, que contavam com os Centros Populares de Cultura da UNE (CPCs) (HOLLANDA, 1982), o feminismo revelava-se "na esfera doméstica, no trabalho e em todas as esferas em que mulheres buscam recriar as relações interpessoais sob um prisma onde o feminino não seja o menos, o desvalorizado" (ALVES e PITANGUY, 1982: 9).

Dentro dos movimentos sociais, as posições eram ambíguas com relação à condição da mulher. Tanto no anarquismo quanto no marxismo, a muIher era incorporada ao espaço público como companheira revolucionária, porém, não viam a dominação masculina como um problema diferente da dominação de classes. Mas se por um lado "é verdadeira a distância entre estes movimentos libertários e o feminismo, por outro, as próprias ideologias que o professavam diminuíam o espaço do preconceito contra as muIheres, permitindo que muitas delas se expressassem" (PINTO, 2003: 34).

Contudo, no tocante ao feminismo, já em meados da década de 1960, o Brasil tinha um forte movimento de mulheres inserido nas classes médias e populares, sendo este com atuação ao longo de toda a duração do governo militar:

Esse é um fenômeno anterior à década de 1970 e que continuou a existir paralelamente a todo o desenvolvimento do feminismo. Se não se pode tratar os movimentos de mulheres como algo totalmente dissociado do movimento feminista, deve-se reter de qualquer forma sua especificidade: foram 
movimentos organizados não para pôr em xeque a condição de opressão da mulher, como no caso do feminismo, mas para, a partir da própria condição de dona-de-casa, esposa e mãe, intervir no mundo público. São exemplos dessas organizações os movimentos contra a carestia, os clubes de mães, o movimento pela anistia, entre muitos outros (PINTO, 2003: 43).

Estes movimentos não eram necessariamente feministas, mas com o passar do tempo serão movimentos que se aproximarão, porém, este não era o caso, ainda, do período pré-golpe militar.

Adentrado o golpe de 1964, um paradoxo se fazia presente no movimento feminista brasileiro: por um lado "teve de administrar as tensões entre uma perspectiva autonomista e sua profunda ligação com a luta contra a ditadura militar", ao passo em que, em contrapartida, era "visto pelos integrantes da mesma luta como um sério desvio pequeno-burguês":

O movimento feminista, em países como o Brasil, não pode escapar dessa dupla face do problema: por um lado, se organiza a partir do reconhecimento de que ser mulher, tanto no espaço público quanto no privado, acarreta consequências definitivas para a vida e que, portanto, há uma luta específica, a da transformação das relações de gênero. Por outro lado, há uma consciência muito clara por parte dos grupos organizados de que existe no Brasil uma grande questão: a fome, a miséria, enfim, a desigualdade social, e que este não é um problema que pode ficar fora de qualquer luta específica. Principalmente na luta das mulheres e dos negros, a questão da desigualdade social é central (PINTO, 2003: 45)

Se as questões de ordens sociais maiores causavam paradoxos para o movimento feminista dentro da luta de classes e da desigualdade social, no interior do próprio movimento feminista se encontravam contradições, pois o termo "feminino" ou "mulher" não davam conta das diferenças e desigualdades quando se tratava de mulheres pobres, negras, sem-terra; sendo uma espécie de mulher universal pequeno-burguesa a ser confrontada por outras mazelas sociais.

Mas dentro das lutas sociais empreendidas pelo movimento feminista, uma conquista é adquirida, em 1962, com a aprovação do Estatuto da Mulher Casada, e em 1964 as duas partes do casal (patriarcal) passam a ter os mesmos impedimentos legais, necessitando do consentimento mútuo para dar fianças, alienar imóveis ou oferecer bens em hipotecas, entre outros.

Com o acirramento do regime militar sobre grupos organizados e aglome- 
rações sociais, as conquistas femininas foram freadas e a sociedade patriarcal reforçada. O ano de 1968, com a edição do Al-5, até o final do governo Médici, foram os mais difíceis para os diversos setores sociais organizados, dificultando a articulação das feministas brasileiras, que se encontravam exiladas na Europa e nos Estados Unidos, com os grupos de mulheres que procuravam iniciar um confronto contra a dominação masculina em nosso país. Organizado em pequenos grupos em reuniões caseiras, o feminismo caminhava a passos lentos no contexto brasileiro.

Até por estas condições sociais em que se encontrava o feminismo, podemos afirmar que a revista Realidade era uma voz de diversas causas femininas, e voz com uma penetração profunda nas classes médias e na elite brasileira. Os temas sobre o divórcio, o desquite, o espaço dado ao comportamento de personalidades internacionais femininas associadas ao feminismo fora do Brasil, a questão da revolução sexual dos jovens e um novo tipo de mulher a ser almejada pela juventude eram temas constantes. Em janeiro de 1966, a edição de Realidade dedicada às mulheres brasileiras é censurada sem sequer ter um sistema de censura estabelecido pelo governo nacional, sendo realizada pelo Juizado de Menores do Rio de Janeiro e de São Paulo.

Edições dedicadas aos negros, e uma em especial à homossexualidade, demonstram que apesar de as lutas sociais estarem sob vigilância, este veículo estava conectado com as demandas dos grupos urbanos, agora desarticulados politicamente. Perceberemos, no devido momento, que diversos membros da Realidade eram ligados a movimentos de esquerda, alguns mesmo atuantes nas guerrilhas que se deflagraram ao longo de todo o regime militar.

Mas ainda que Realidade expusesse à sociedade algumas causas importantes para a condição da mulher, as organizações sociais eram pouco viáveis. O movimento feminista no país será desarticulado pela simples falta de contato e conexão entre as partes interessadas, ou seja, mal chegará a se articular.

Isto até o ano de 1972, "quando começaram a aparecer nas cidades de São Paulo e Rio de Janeiro os primeiros grupos feministas inspirados no feminismo nascente no hemisfério norte" (PINTO, 2003: 49). Eram grupos de reflexão, organizados de maneira informal, reunindo mulheres que 
já se conheciam em um espaço privado. Apesar de suas discussões sobre a condição de submissão feminina, a sexualidade era um tema tabu entre tais mulheres.

Mais uma vez, nesse ponto, podemos entender a editoria da Realidade como à frente das discussões, mesmo aquelas encabeçada pelas feministas. Conectados com o mundo, informados sobre o que se passa comunicacionalmente no hemisfério norte, os repórteres da Realidade estão interessados no comportamento das mulheres com relação a seus maridos, mas também da juventude que deseja uma mudança comportamental no tocante à sexualidade. Sem qualquer articulação social organizada, já que o governo Médici sufocou seus adversários políticos, tanto no campo ideológico quanto no próprio confronto armado, a Realidade ainda era um espaço de diálogo com os anseios de mudança. Porém a revista adotava estratégias como, por exemplo, tratar do feminismo nos Estados Unidos ou elaborar uma longa matéria sobre um país ditatorial na América Latina, com claras alusões ao que se passava em nosso país.

Em outra vertente social, os grupos de mulheres se reuniam, com famílias unidas, por vezes mães católicas, discutindo a sua relação no lar junto a filhas que queriam mais liberdade sexual. "Enquanto no resto do mundo ocidental as mulheres procuravam discutir sua posição na sociedade, seu corpo e seu prazer, um punhado de mulheres brasileiras fazia a mesma coisa, mas pedindo desculpas" (PINTO, 2003: 51).

Outra contingência histórica que irá contribuir para o desenvolvimento do feminismo no Brasil é, contraditoriamente, o exílio. Com o grande número de brasileiros que partiram para o exterior a partir de 1964, mas, principalmente, após 1968, diversas mulheres brasileiras entraram em contato com jovens militantes em plena agitação social e cultural, extremamente distintas daquela que as mulheres brasileiras estavam acostumadas a viver no Brasil.

O feminismo é definido em oposição direta ao patriarcalismo e à dominação masculina, pois diz respeito à condição da mulher nas maiores e menores estruturas em que ela está visivelmente submetida ao homem. Tratavam-se de organizações feministas que se constituíram em "redes de sustentação, emprestando sua experiência e fornecendo os materiais dis- 
cursivos para que a cultura feminina pudesse emergir e solapar o patriarcalismo no seu mais forte reduto: a mente das mulheres" (CASTELLS, 2002: 217). Esta rede de sustentação é o que acelerará o movimento feminista no país na segunda metade da década de 1970. Entretanto, foi exatamente nesse fornecimento emprestado de material discursivo que o período mais coercitivo do regime militar atingiu o movimento, pois a circulação da palavra política não interessava aos militares, já que não circulando, eliminava a sua eficácia (OLIVEIRA, 1998).

Todavia, foi no cenário do exílio que mulheres brasileiras entraram em contato com ideários feministas, tendo sido alvo de grande desconfiança por seus companheiros homens. "Na verdade, a esquerda exilada, marxista e masculina, via no feminismo uma dupla ameaça: à unidade da luta do proletariado para derrotar o capitalismo e ao próprio poder que os homens exerciam dentro dessa organização e em suas relações pessoais" (PINTO, 2003: 53). E, apesar dos esforços do regime militar em coibir a circulação das ideologias e ideias, as feministas brasileiras na Europa e, especialmente, em Paris não cessavam de enviar material para o Brasil, entrando em contato com as feministas principalmente do Rio de Janeiro e de São Paulo, já que, no exílio, gozavam de liberdade e possuíam uma atuação ativa, organizando comissões e assembleias.

Foi apenas em 1975, com o governo de Geisel, que o movimento feminista brasileiro gozou de grande expansão. A Organização das Nações Unidas (ONU) decidiu que aquele seria o Ano Internacional da Mulher, com eventos internacionais organizados pela mesma entidade no Brasil, atingindo grande êxito, ajudando a institucionalizar os movimentos e permitindo maior inserção nos discursos e práticas da esquerda.

A partir de então, o feminismo evolui, não sem trazer em si contradições e embates internos, pois, aos poucos, novos matizes de gênero vão se inserindo na práxis discursiva do movimento, como a questão das lésbicas, das mulheres negras e outras tantas, que tornam a definição de gênero sempre dinâmica e o feminismo em constante movimento. Durante este momento histórico, a revista Realidade estava em franco declínio. Sua linguagem e narrativa havia se fragmentado na busca por sobrevivência no mercado. Era uma revista comum, em um nível abaixo das suas concorrentes. Se antes 
participou da construção inicial destas conquistas para as causas femininas, agora apenas agonizava esperando seu fim, que viria em março de 1976. Enquanto isso, era nas academias que o feminismo travava outra frente de sua luta.

\section{Referências}

ALVES, Branca Moreira e PITANGUY, Jacqueline. O que é feminismo, São Paulo: Brasiliense, 1982.

CASTELLS, Manuel. O Poder da Identidade, vol. II, São Paulo: Paz e Terra, 2002.

HALL, Stuart. A Identidade Cultural na Pós-Modernidade, Rio de Janeiro: DP\&A, 2006.

HOLLANDA, H. B. \& GONÇALVES, M. A. Cultura e participação nos anos 60, 8 ed. São Paulo: Brasiliense, 1990. (Tudo é História).

OLIVEIRA, S. C. Irreverências mil pra noite do Brasil: imagens do regime militar nas canções engajadas, Mestrado [dissertação]. Curso de PósGraduação em História, Universidade Federal do Paraná, Curitiba, 1998. PINTO, Celi. Uma História do Feminismo no Brasil. São Paulo: Perseu Abramo, 2002. 